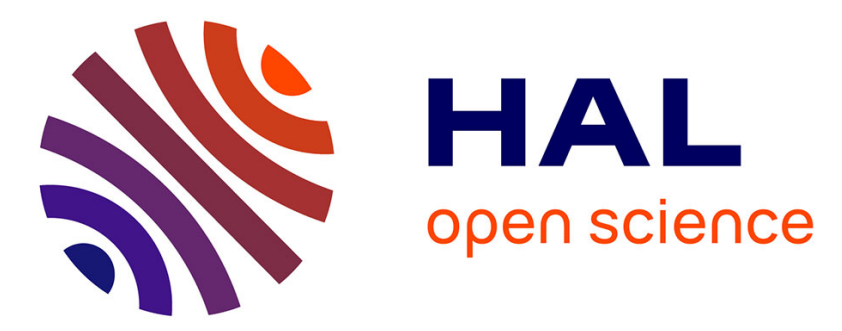

\title{
Correction of the FSHD myoblast differentiation defect by fusion with healthy myoblasts
}

Carla Dib, Yara Bou Saada, Petr Dmitriev, Catherine Richon, Philippe Dessen, Dalila D. Laoudj-Chenivesse, Gilles Carnac, Marc Lipinski, Yegor Vassetzky

\section{To cite this version:}

Carla Dib, Yara Bou Saada, Petr Dmitriev, Catherine Richon, Philippe Dessen, et al.. Correction of the FSHD myoblast differentiation defect by fusion with healthy myoblasts. Journal of Cellular Physiology, 2016, 231 (1), pp.62 - 71. 10.1002/jcp.25110 . hal-01804854

\section{HAL Id: hal-01804854 \\ https://hal.umontpellier.fr/hal-01804854}

Submitted on 4 Dec 2019

HAL is a multi-disciplinary open access archive for the deposit and dissemination of scientific research documents, whether they are published or not. The documents may come from teaching and research institutions in France or abroad, or from public or private research centers.
L'archive ouverte pluridisciplinaire HAL, est destinée au dépôt et à la diffusion de documents scientifiques de niveau recherche, publiés ou non, émanant des établissements d'enseignement et de recherche français ou étrangers, des laboratoires publics ou privés. 


\title{
Correction of the FSHD Myoblast Differentiation Defect by Fusion With Healthy Myoblasts
}

\author{
CARLA DIB, ' YARA BOU SAADA,' PETR DMITRIEV, ' CATHERINE RICHON, ${ }^{2}$ \\ PHILIPPE DESSEN, ${ }^{2}$ DALILA LAOUDJ-CHENIVESSE, ${ }^{3}$ GILLES CARNAC, ${ }^{3}$ MARC LIPINSKI, ${ }^{\prime}$ \\ AND YEGOR S. VASSETZKY'*
}

'UMR 8126, University of Paris-Sud, CNRS, Institut de Cancérologie Gustave-Roussy, F-94805 Villejuif, France

${ }^{2}$ Functional Genomics Unit, Institut de Cancérologie Gustave-Roussy, F-94805 Villejuif, France

${ }^{3}$ INSERM U-1046, 37 I Avenue du Doyen Gaston Giraud, F-34295 Montpellier, France

Facioscapulohumeral dystrophy (FSHD) is a neuromuscular disease with a prevalence that could reach I in 8,000 characterized by progressive asymmetric muscle weakness. Myoblasts isolated from FSHD muscles exhibit morphological differentiation defects and show a distinct transcription profile. These abnormalities may be linked to the muscle weakness in FSHD patients. We have tested whether fusion of FSHD myoblasts with primary myoblasts isolated from healthy individuals could correct the differentiation defects. Our results show that the number of hybrid myotubes with normal phenotype increased with the percentage of normal myoblasts initially cultured. We demonstrated that a minimum of $50 \%$ of normal nuclei is required for a phenotypic correction of the FSHD phenotype. Moreover, transcriptomic profiles of phenotypically corrected hybrid myotubes showed that the expression of deregulated genes in FSHD myotubes became almost normal. The number of deregulated pathways also decreased from 39 in FSHD myotubes to one in hybrid myotubes formed with $40 \% \mathrm{FSHD}$ and $60 \%$ normal myoblasts. We thus propose that while phenotypical and functional correction of FSHD is feasible, it requires more than $50 \%$ of normal myoblasts, it creates limitations for cell therapy in the FSHD context.

Facioscapulohumeral muscular dystrophy (FSHD) is an autosomal dominant neuromuscular disease with a prevalence that could reach I in 8,000 (Deenen et al., 20I4). Clinically, FSHD is characterized by a progressive weakness and atrophy of the facial muscles and the shoulder girdle. There is a wide variability in the spectrum of the disease, however, with clinical features ranging from a very mild muscle weakness - with some patients even unaware of being affected-to severe symptoms that make patients wheelchair-dependent.

Myoblasts isolated from FSHD patients exhibit defects in their morphological differentiation. Whereas normal myoblasts fuse to form branched myotubes whose nuclei are aligned, the myotubes resulting from FSHD myoblast fusions are either thin and atrophic with nuclei aligned, or large with a random distribution of the nuclei (Barro et al., 2010a). These abnormalities may be a cause for the muscle weakness in FSHD patients.

The major genetic form of FSHD has been mapped to the subtelomeric region of the long arm of chromosome 4 (Wijmenga et al., 1991). In this region, three abnormalities have been specifically associated with FSHD: a partial deletion within D4Z4, a polymorphic macrosatellite repeat array; the presence of SSLP-16I, a specific simple sequence length polymorphism; and that of the $4 q A$ allele (reviewed in (Tawil et al., 20/4)). This three feature-combination leads to large-scale epigenetic changes in the $4 q 35$ chromosomal region in FSHD patients (Van et al., 2003; Petrov et al., 2006, 2008; Cabianca et al., 20I2; Kisseljova et al., 20I4) which releases the inhibition otherwise imposed on the expression of DUX4, a gene contained in the D4Z4 repeat and possibly also leads to the overexpression of $A N T I, F R G I, D U X 4 C$, and FRG2, five genes positioned centromerically to D4Z4 and which each has been implicated for a role in FSHD: (Gabellini et al., 2002; Rijkers and deidda, 2004; Masny and Chan, 2010; Dmitriev et al., 20I la).
Among the D4Z4-proximal genes, some affect gene transcription. Thus, DUX4 and DUX4c encode homeobox transcription factors and $F R G I$ a splicing factor. Their altered expression can result in a wide transcriptional deregulation in FSHD myoblasts. Indeed, transcriptomic studies have revealed hundreds of genes deregulated in FSHD myoblasts and myotubes as compared to controls. In these studies, affected pathways included myogenesis (Winokur et al., 2003; Tsumagari et al., 20I I), muscle structure, mitochondrial function (Tsumagari et al., 20I I), stress responses, signal transduction (Tsumagari et al., 20l I), the immune system (Winokur et al., 2003; Arashiro et al., 2009; Tsumagari et al., $20 \mathrm{II}$ ) and the cytoskeleton (Dmitriev et al., $20 \mathrm{I} \mathrm{l} \mathrm{b;} \mathrm{Tassin} \mathrm{et} \mathrm{al.,}$ 2012). Interestingly, some of these pathways can be deregulated in cells overexpressing an ectopic version of the DUX4 gene (Geng et al., 20I2).

Abbreviations: FSHD, facioscapulohumeral dystrophy; MFI, myogenic fusion index; DMI, deformed myotube index.

Current address of Petr Dmitriev is IRIBHM, Université Libre de Bruxelles, 1070 Bruxelles, Belgium.

Contract grant sponsor: Association Française contre les Myopathies (AFM).

*Correspondence to: Yegor S. Vassetzky, UMR 8I26, University of Paris-Sud, CNRS, Institut de Cancérologie Gustave-Roussy, F94805 Villejuif, France. E-mail: vassetzky@igr.fr 
The fusion of myoblasts, a crucial event in muscle differentiation, is a regulated multistep process which in vertebrates is triggered in response to muscle tissue damages. For the tissue to regenerate, muscle satellite cells must proliferate and fuse. This is accompanied by a coordinated regulation of numerous pathways orchestrated by master gene regulators including MyoD and Myf5 with the accompanying expression of a few specific miRNAs (Dmitriev et al., 2013).

Here, we have considered satellite cells as possible targets for an innovative therapeutical approach in FSHD, as suggested in (Bareja and Billin, 2013). Our approach was based on the idea that fusing normal and FSHD myoblasts could result in a normalized phenotype in hybrid cells. To study the feasibility of such an approach, hybrid myofibers have been produced in vitro and examined for their phenotypic and transcriptional features. Our results show that the number of hybrid myotubes with normal phenotype increases with the percentage of normal myoblasts initially culture and for this FSHD phenotypic correction a minimum of $50 \%$ of normal nuclei is required. Moreover, transcriptomic profiles of phenotypically corrected hybrid myotubes show that the expression of deregulated genes in FSHD myotubes became almost normal.

\section{Materials and Methods}

\section{Data of FSHD patients and healthy individuals}

Primary human myoblasts were isolated from samples of skeletal muscle obtained with the patients' consent in accordance with the French and European legislation and cultured as described (Barro et al., 2010a). Ethics approval was obtained from Montpellier University Ethics Committee. The primary human myoblasts are described in Table I.

\section{Proliferation and differentiation of myotubes}

Myoblasts were seeded at $10^{6}$ cells/dish onto $35 \mathrm{~mm}$ collagencoated dishes and cultured in growth medium (DMEM containing $20 \%$ FBS). Cells were counted using a cell counter (Vi-cell Beckman Coulter, Villepinte, France). Myogenic differentiation of confluent cells was induced after $2 \mathrm{hr}$ by changing to DMEM containing $2 \%$ FBS (differentiation medium). Cells were kept in differentiation medium for 4 days. At day 4 after induction of differentiation, cells were immunostained with anti-troponin $T$ antibody coupled with DAPI (see Immunostaining for details) to visualize myotubes and nuclei in the culture. All experiments were carried out at passages between 2,3 , and 4 to avoid cell senescence.

\section{Immunostaining}

Human myotubes were fixed in $0.5 \%$ PBS/BSA containing $2 \%$ paraformaldehyde (Electron Microscopy Sciences, Hatfield, PA) and treated with $0.5 \%$ PBS/BSA containing $0.5 \%$ triton $X-100$. Myotubes were then labeled with monoclonal anti-troponin $T$ (mAb, Sigma-Aldrich, St. Louis, MO) antibodies diluted at I/50 and revealed using anti-mouse Alexa-488 conjugated antibodies (Molecular Probes-Life technologies, Saint-Aubin, France) diluted at $1 / 100$ from an initial concentration of $2 \mathrm{mg} / \mathrm{ml}$. Nuclei were visualized by DAPI staining. All the washes were done with

TABLE I. Normal and FSHD cell lines used in the present study

\begin{tabular}{ccccc}
\hline Name & Sex & Age (years) & D4Z4 copy number & Muscle \\
\hline M048 & M & 39 & 6 & Vastus lateralis \\
M054 & M & 25 & 4 & Vastus lateralis \\
N045 & F & 35 & NA & Quadriceps \\
N039 & F & 23 & NA & Paravertebral \\
N042 & F & 24 & NA & Quadriceps \\
\hline
\end{tabular}

$0.5 \%$ PBS/BSA. The stained myotubes were observed under a fluorescent microscope (Microvision instruments, Hagerstown, MD) (Excitation/Emission:488/519 nm), and images from adjacent fields of view were stitched together by using Cartograph (Microvision) to create one large image of the specimen.

\section{Chromosome $Y$ fluorescence in-situ hybridization}

Myotubes grown in Petri dishes were incubated in 2XSSC for $15 \mathrm{~min}$ at room temperature and treated in $70 \%$ formamide at $60^{\circ} \mathrm{C}$ for DNA denaturation. $10 \mu \mathrm{l}$ of chromosome $Y$ probe (Cytocell, Cambridge, United Kingdom) for each test ( $28 \mathrm{ng} /$ test) was heated at $37^{\circ} \mathrm{C}$ for $10 \mathrm{~min}$ then dropped on myotubes. DNA was denatured at $75^{\circ} \mathrm{C}$ for $10 \mathrm{~min}$. Hybridization was done in a wet chamber overnight in the dark at $37^{\circ} \mathrm{C}$. Post hybridization washings were done with $50 \%$ Formamide/2X SSC and 2 X SSC. Nuclei were visualized by DAPI staining.

\section{Analysis of myotubes' fusion}

Fusion competence was determined after 4 days of differentiation using the Myotube Fusion Index (MFI). The myogenic fusion index (MFI) was determined by dividing the number of nuclei in multinucleated myotubes by the total number of nuclei in a given microscopic field. Three fields per culture were counted in three independent cultures (a total of I,500 nuclei per cell line) using Image J, Java-based image processing program developed at the National Institutes of Health.

The Deformed Myotube Index (DMI) was calculated as the proportion of myotubes with a deformed morphology characterized by an abnormal repartition of nuclei. 100 myotubes were counted per condition in three independent experiments. Statistical treatment of the data was performed using Chi square test.

\section{Quantitative analysis of FSHD nuclei in hybrid myotubes}

FSHD nuclei were counted in phenotypically corrected and noncorrected hybrid myotubes and the percentage of FSHD and normal nuclei was established. An average of 24 myotubes per condition was scored in three independent experiments.

\section{RNA isolation}

The RNA isolation from phenotypically corrected myotubes was performed by TriPrep NucleoSpin ${ }^{\circledR}$ kit (Macherey-Nagel) according to manufacturer's instructions.

\section{Reverse transcription-PCR assays}

$100 \mathrm{ng}$ of total RNA was reverse transcribed with random hexamers (Fermentas) using the following cycling protocol: $10 \mathrm{~min}$ $25^{\circ} \mathrm{C}, 60 \mathrm{~min} 42^{\circ} \mathrm{C}, 10 \mathrm{~min} 70^{\circ} \mathrm{C}, 4^{\circ} \mathrm{C}$. Quantitative PCR amplifications were done with 5 ng of $C D N A$ using the following primers: FRG2-forward: GCCCAGGTGTGGGCACAGCAGA and FRG2-reverse: CGGGTCCACACCCGTGTCGTCT;

GAPDH-forward: TGATGACATCAAGAAGGTGGTGAAG and GAPDH-reverse: TCCTTGGAGGCCATGTGGGCCAT applying the following cycling protocol: $10 \mathrm{~min} 95^{\circ} \mathrm{C}, 40$ cycles $95^{\circ} \mathrm{C}$ then $60^{\circ} \mathrm{C}$ and melting curve. Amplification of glyceraldehyde 3-phosphate dehydrogenase (GAPDH) was used as an internal control. The number of copies of the target sequence in each sample was determined by relative quantification using the comparative $C_{T}\left(\Delta \Delta C_{T}\right)$ method. Statistical treatment of the data was performed using a two-sided Student's $t$-test. The quantity and quality of RNA for RT-PCR were determined by the NanoDrop 2000c Spectrophotometer (Thermo Fisher Scientific, Waltham, MA). 


\section{Microarray gene expression profiling}

The quantity and quality of RNA for transcriptome analysis were determined by Agilent 2100 bioanalyzer (Santa Clara, CA). The microarray gene expression profiling was performed using Agilent long oligonucleotide technology (Human genome $8 \times 60 \mathrm{~K}$, design 028004) based on a single color analysis method (Cy3).

Experiments were performed in biological duplicate. After normalization with the Limma procedure, the intensities were imported into the Biometric Research Branch ( $\mathrm{BrB})$ Arrays Tools software version 4.4 .0 (November 20l4) (http://linus.nci.nih.gov/ BRB-ArrayTools.html). Class Comparisons of each corrected samples were performed at a $P$-value of 0.001 , and a fold-change of two by comparing corrected and normal samples (low intensities $<50$ and probes on chromosomes $X$ and $Y$ were filtered). The genes that were differentially expressed among the two classes were identified using a random-variance $t$-test (an improvement over the standard separate $t$-test as it permits sharing information among genes about within-class variation without assuming that all genes have the same variance). Genes were considered statistically significant if their $P$-value was $<0.001$. The data are submitted in the EMBL-EBI database with the access number E-MTAB-3658.

\section{Pathway class comparison}

We identified groups of genes of KEGG pathways whose expression was differentially regulated among the classes. By analyzing KEGG groups, rather than individual genes, we were able to reduce the number of tests conducted, and to enable findings among biologically related genes to reinforce each other. For each KEGG group we computed the number $n$ of genes represented on the microarray in that group, and the statistical significance $\pi$ value for each gene in the group (threshold of 0.005 ). For a group, two statistics are computed that summarize the $P$-values for genes in the group; the Fisher (LS) statistic and the Kolmogorov-Smirnov (KS) statistic. For each KEGG category, two significance levels are computed, corresponding to the two summary statistics. We considered a KEGG category significantly differentially regulated if the two significance levels were less than 0.01 . We considered all KEGG categories with between 5 and 100 genes represented on the array. Some of the categories were overlapping.

\section{Correlation with the dilution effect}

To analyze the effect of a selection of 240 genes (a part of the signature of $100 \%$ disease versus $100 \%$ normal samples at a $P$-value of $0.00 \mathrm{I}$ and a fold change $>$ I.5), we have explored the Pearson correlation between experimental expressions of each gene at 0 , $40,60,80$, and $100 \%$ disease state) with a theoretical set of values defined by the proportion of disease (between 0 and $100 \%$ ). Genes with correlation coefficients between 0.8 and I were considered to be correlated to dilution.

\section{Results}

\section{Phenotypic analysis of hybrid myotubes}

Myotubes are formed from muscle precursors which express the CD56 surface antigen. In FSHD, myotubes are formed from myoblasts but they are either atrophic or disorganized (Fig. IB) (Barro et al., 20I0a). Since fusion occurs in FSHD as well as in normal myoblasts, we tested whether a fusion between a mixture of normal and FSHD myoblasts would produce myotubes with normal or FSHD features. In order to control the proportion of normal and FSHD cells in each myotube, we used primary CD56+ FSHD myoblasts from men and normal myoblasts from women. The myoblasts were isolated and highly purified (90-95\% of desmin-positive cells in both FSHD and control cell cultures) as previously described (Barro et al., 2010a). Their properties are summarized in Table I. We have chosen to carry out experiments on cell lines that were described to form disorganized myotubes (Barro et al., 20l 0b). Once differentiated into myotubes, they are easily distinguished from hybrid myotubes with normal phenotype. In the first series of experiments, we fused the myoblast cell-line MO54 which has been derived from an FSHD patient with NO42 normal myoblasts. Different combinations were tested varying from 0 to $100 \%$ of either cell line. These primary cells were plated onto collagen-coated petri dishes at a density of $10^{6}$ cells per petri dish and induced to differentiate two hours after seeding. Four days later, they were collected and stained for the differentiation marker troponin and the presence of the Y chromosome. Typical patterns of troponin-stained myotubes generated from either $100 \%$ normal cells or from FSHD subjects are shown in Figure IA and B. As expected, normal myotubes were found branched and with aligned nuclei while FSHD myotubes were disorganized with either randomly localized nuclei or node-like structures with circular distribution of nuclei. $100 \%$ of these nuclei were stained for $Y$ chromosome (data not shown).

Hybrid myotubes formed from a mixture containing only $20 \%$ normal myoblasts could not be distinguished from myotubes formed with $100 \%$ FSHD myoblasts. When the proportion of normal myoblasts increased in the starting mixture, the phenotype of the resulting myotubes improved. As seen in Figure IC-F, the resulting hybrid myotubes exhibited a phenotype that was closer to normal as the proportion of normal myoblasts was more important in the initial combination. Indeed, when the initial mixture included $20 \%$ FSHD myoblasts, the myotube phenotype we observed was very similar to the control with $100 \%$ normal cells. Interestingly, the phenotypes were either normal or disorganized; no intermediary forms could be observed.

We then concentrated on two distinct combinations with 40 or $60 \%$ normal and FSHD cells, respectively (N40M60: $40 \%$ normal, 60\% FSHD; N60M40: 60\% normal, 40\% FSHD). In these experiments, four different cell lines were used, two from FSHD men (M048 and M054), two (N039, N045) from healthy women. Resulting hybrid myotubes were stained for troponin to quantify disorganized phenotype using the deformed myotubes index (DMI) (Yip and Picketts, 2003) that determins the proportion of myotubes with abnormal phenotype in the culture. One hundred myotubes have been scored in each combination (each FSHD cell line was combined separately with the two normal myoblasts cell lines). The proportion in FSHD had an average of $63.5 \%$ whereas the DMI decreased to $25.5 \%$ in N40M60 combination and $14 \%$ in N60M40 to approach to the DMI in controls which is $1 \%$ in agreement with our first observations of a relationship between the phenotype of the hybrid myotubes and the starting proportion of defective and normal myoblasts in the cell mix (Fig. IH).

To assess fusion competence, we calculated the myogenic fusion index (MFI) of all the cell lines we used in our experiments (MO54, MO48, NO42, NO39, and NO45). MFI is the ratio between the nuclei present in myotubes versus the total number of nuclei in a given field, where a myotube is defined as a muscle cell containing at least three or more nuclei. We obtained $72 \%$ and $77 \%$ for both FSHD (M) and Normal (N) cell cultures, respectively (Fig. IG). This indicates that fusion occurs similarly in normal and FSHD myoblasts.

\section{A proportion of $50 \%$ normal myoblasts is compatible with a normal phenotype in hybrid myotubes}

To better characterize the parental origin of the cells which form myotubes after cell fusion, we used fluorescence in situ hybridization (FISH) to stain for the Y chromosome. Nuclei derived from male FSHD myoblasts were thus revealed in the 


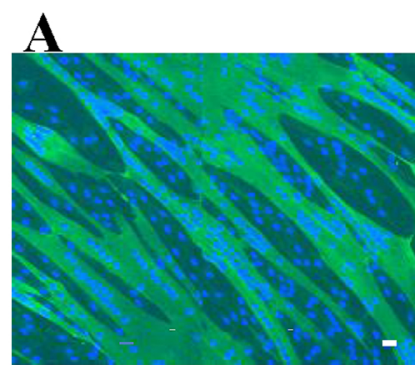

NORMAL

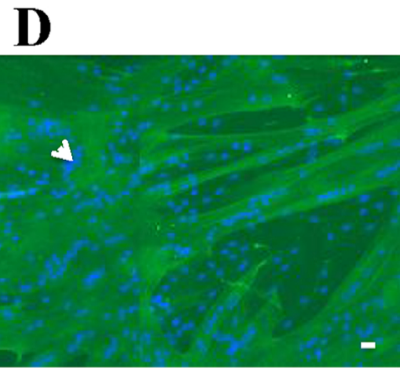

N40M60

G

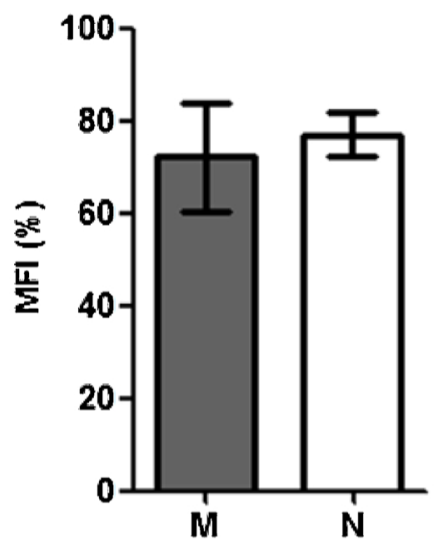

B

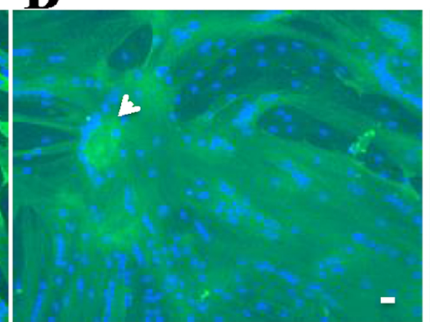

FSHD

E

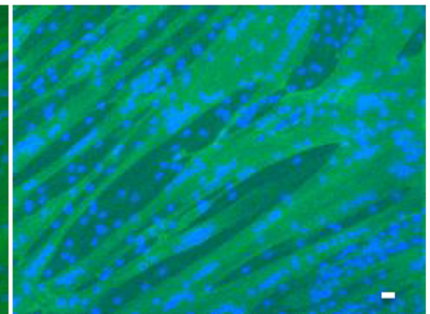

N60M40

H

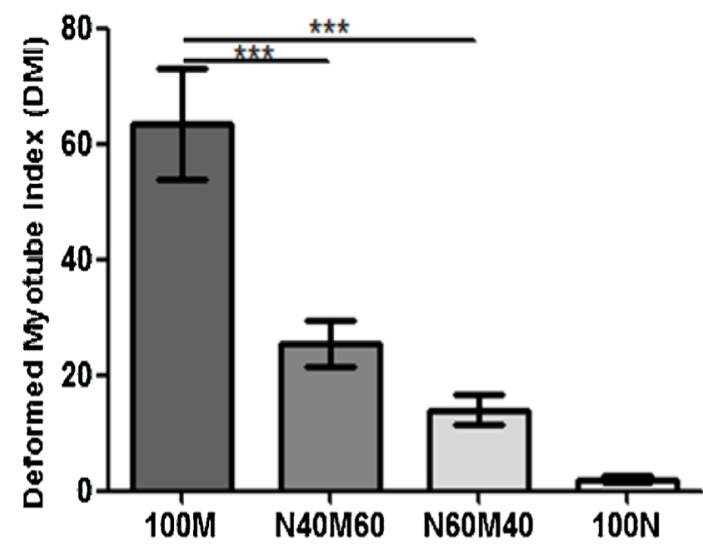

Fig. I. Analysis of myotube phenotype in normal/FSHD hybrid myotubes. The normal and FSHD myoblasts were grown alone or mixed in different proportions and induced to differentiate. The phenotype of myotubes was analyzed under a fluorescent microscope after the troponin T staining. (A), Normal myotubes have branched myotubes with aligned nuclei. (B) FSHD cells produce large disorganized myotubes with abnormal nuclei repartition; (C), Hybrid myotubes formed with $20 \%$ of normal myoblasts are phenotypically identical to FSHD myotubes; (D-F) the phenotype becomes progressively normal with the increase in the proportion of normal myoblasts in the culture; nuclei become aligned, and the number of node-like structures decreases. Node-like structures are indicated with arrows. Immunofluorescence with an anti-troponin T antibody (green) and DAPI nuclear staining (blue); bar $=10 \mu \mathrm{m}$. (G) Myogenic Fusion Index (MFI) of FSHD and normal cultures. MFI averages for both FSHD (M) and Normal (N) cell cultures are $72 \%$ and $77 \%$, respectively. Nuclei of three fields per culture were counted in three independent cultures for each cell line (I,500 nuclei). (H) Deformed Myotube Index (DMI) of FSHD, hybrid and control cultures. The proportion of deformed myotubes decreased withthe percentage of normal myoblasts initially seeded, while the proportion of myotubes with normal phenotype increased. An average of 100 myotubes per condition was scored in three independent experiments; ${ }^{* * *}$, $\mathbf{P}<\mathbf{0 . 0 0 1}$.

hybrid myotubes generated in vitro. Figure $2 \mathrm{~A}$ shows such an example of $Y$ chromosome-containing nuclei present (arrows) in a hybrid myotube. Next the proportion of FSHD-derived vs. normal nuclei was counted in 48 different myotubes, whether looking disorganized or normal. In phenotypically normal myotubes, the average number of FSHD ( $\mathrm{Y}$ chromosomestained) nuclei was similar in both combinations tested with $46 \pm 13 \%$ present in the N40M60 combination and $41 \pm 11 \%$ in the opposite N60M40 combination. In disorganized myotubes, the average proportion of $Y$ chromosome-containing myoblasts was also quite high, in our conditions myotubes with up to $44 \%$ of nuclei lacking a $Y$ chromosome did not exhibit a normal phenotype regardless of the combinations tested (Fig. 2B). Taken together, these data suggest that the presence of greater than $50 \%$ normal cells in a hybrid myotube is compatible with a morphologic phenotype looking normal. 
A

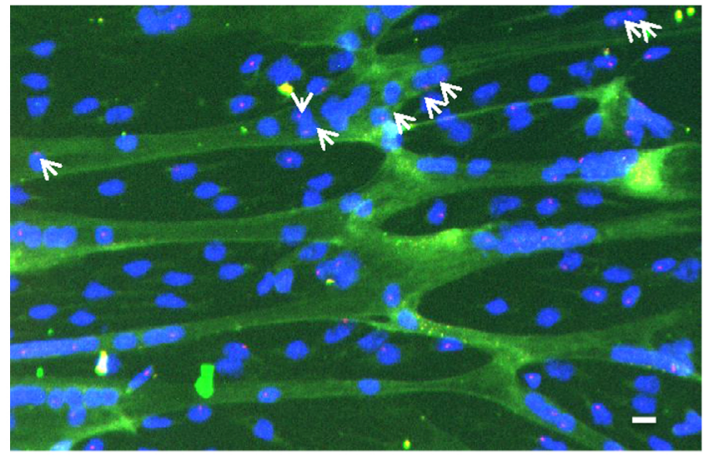

N60M40
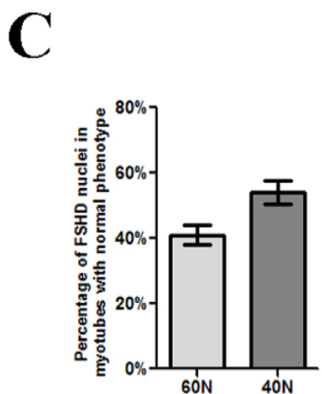

D

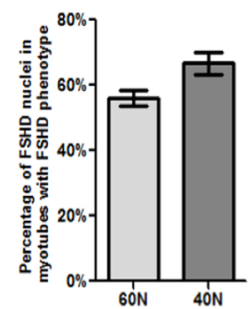

B

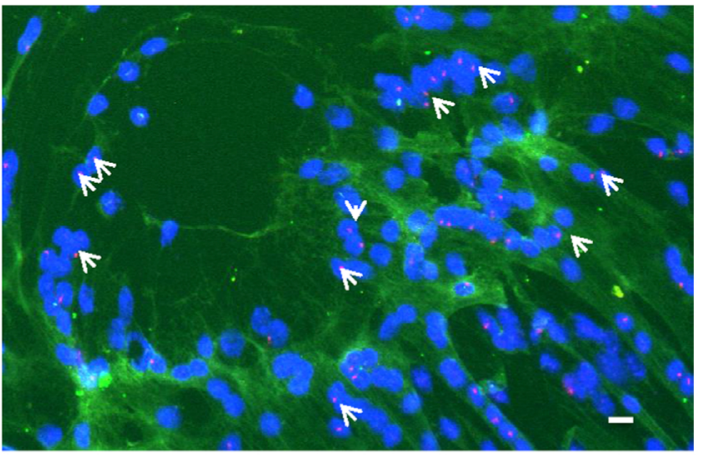

N60M40

E
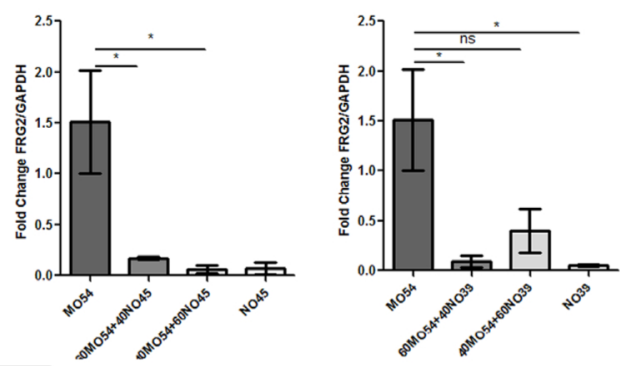

F
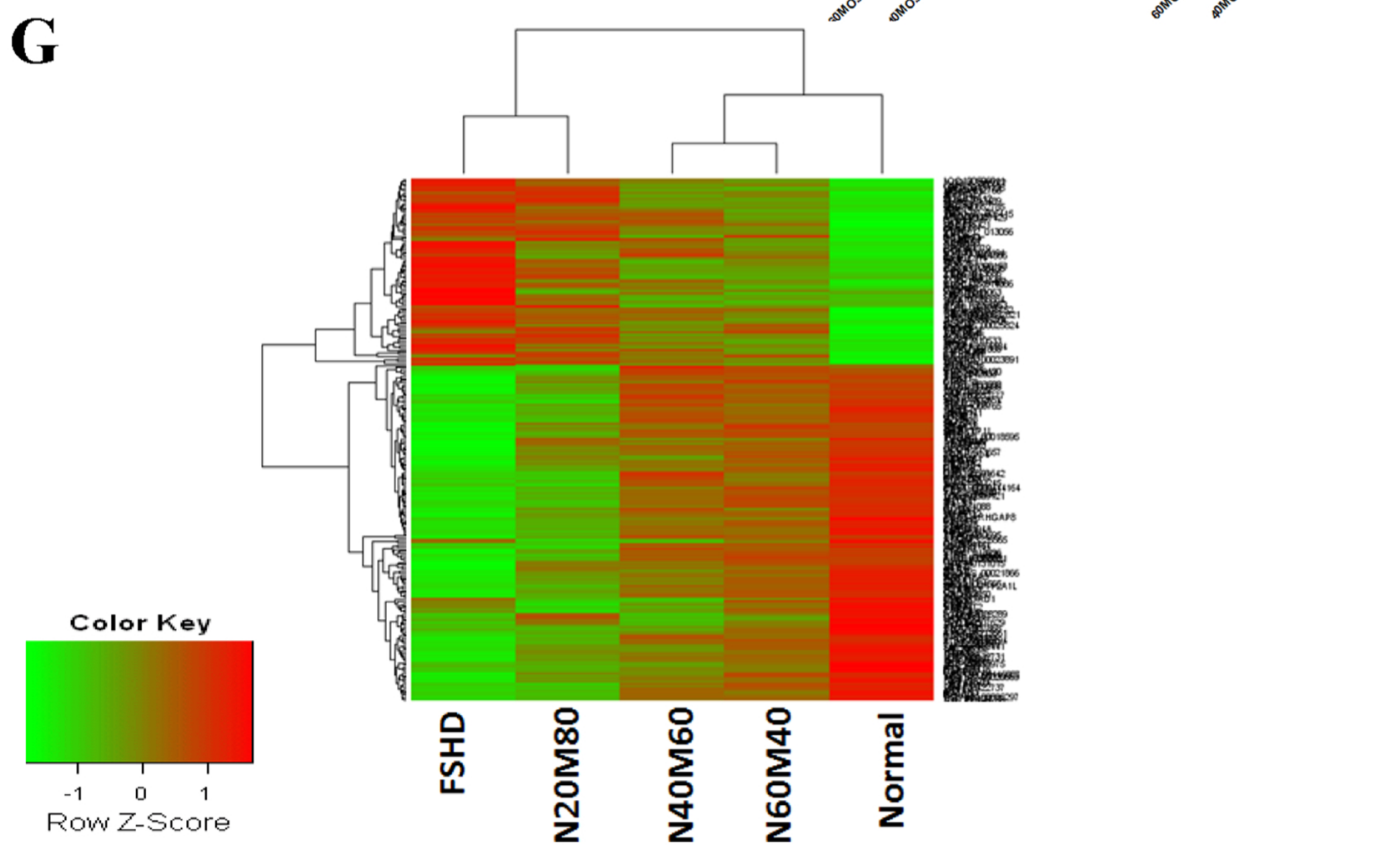

Fig. 2. Analysis of hybrid myotubes. The normal and FSHD myoblasts were mixed in a proportion of N60M40 and induced to differentiate. Both normal and disorganized myotubes could be observed in this condition. The myotubes were analyzed under a fluorescent microscope after the troponin $T$ staining (green). The nuclei originating from the FSHD myoblasts were stained by the probe for $Y$ chromosome (red); (A), hybrid myotubes with normal morphology have branched myotubes with aligned nuclei. (B) disorganized myotubes with abnormal nuclei repartition; bar $=10 \mu \mathrm{m}$; the nuclei originating from the FSHD myoblasts are indicated with arrows; (C and D), Quantification of the nuclei originating from the FSHD myoblasts in normal vs. disorganized myotubes. An average of 24 myotubes per condition was scored in three independent experiments. (E and F), Expression of a FSHD marker gene FRG2 in FSHD, hybrid, and normal myotubes. Error bars indicate standard deviation in three independent experiments. Statistical treatment of the data was performed using a two-sided Student's t-test. (G), This heat map of log ratios expression values (see color key) for genes upregulated or dowregulated $>$ I.5-fold in FSHD myotubes shows that the majority of genes that were upregulated/downregulated in FSHD myotubes (red/green in first column) were downregulated/upregulated in control myotubes (green/red in the corresponding portion of the last column). A correction by dilution is observed in the hybrid myotubes for the majority of genes (in the second, third and fourth column). 
TABLE 2. Expression fold-changes of significantly deregulated genes in FSHD vs. normal and hybrid vs. normal myotubes.

\begin{tabular}{|c|c|c|c|c|c|}
\hline Symbol & Chromosome & $\begin{array}{l}\text { Fold-change } \\
\text { (FSHD/Normal) }\end{array}$ & $\begin{array}{l}\text { Fold-change } \\
\text { (80FSHD/Normal) }\end{array}$ & $\begin{array}{l}\text { Fold-change } \\
\text { (60FSHD/Normal) }\end{array}$ & $\begin{array}{c}\text { Fold-change } \\
\text { (40FSHD/Normal) }\end{array}$ \\
\hline MYOZ2 & chr4 & -2.00 & -1.57 & -1.30 & -1.32 \\
\hline LDB3 & chrlo & $-\underline{2.03}$ & -1.46 & -1.18 & -1.20 \\
\hline NPVF & $\mathrm{chr} 7$ & $-\underline{2.05}$ & -1.74 & -1.25 & -1.24 \\
\hline PIK 3 C2B & chrl & $-\underline{2.05}$ & -1.55 & -1.37 & -1.35 \\
\hline MLLTII & chrl & $-\underline{2.08}$ & -1.60 & -1.33 & -1.33 \\
\hline THBS4 & chr5 & $-\underline{2.08}$ & -1.39 & $-|| 1$. & -1.18 \\
\hline PCDHBI6 & chr5 & -2.08 & -1.79 & -1.38 & -1.22 \\
\hline ATP8AI & $\operatorname{chr} 4$ & $-\overline{2.08}$ & -1.28 & -1.12 & 1.05 \\
\hline A_33_P32I356I & chrl5 & $-\underline{2.09}$ & -1.75 & -1.29 & -1.30 \\
\hline $\mathrm{R} \overline{\mathrm{B}} \mathrm{M} 2 \mathrm{O}$ & chrlo & -2.09 & -1.61 & -1.15 & -1.19 \\
\hline REEPI & chr2 & -2.15 & -1.77 & -1.35 & -1.35 \\
\hline AQPI & chr7 & $-\overline{2.17}$ & $-\underline{2.00}$ & -1.69 & -1.49 \\
\hline SH3BGR & chr2I & -2.18 & -1.50 & -1.09 & -1.14 \\
\hline ZGI6B & chrl 6 & -2.20 & -1.45 & -1.12 & 1.17 \\
\hline LOC339290 & chrl8 & $-\underline{2.23}$ & -1.45 & -1.47 & -1.28 \\
\hline HRC & chrl9 & $-\underline{2.24}$ & -1.45 & -1.27 & -1.31 \\
\hline CTSH & chr I5 & $-\underline{2.26}$ & -1.62 & -1.45 & -1.46 \\
\hline XLOC_I2_OI2925 & chr6 & $-\underline{2.28}$ & -1.48 & -1.39 & -1.20 \\
\hline FZD9 & chr7 & $-\underline{2.33}$ & -1.54 & -1.50 & -1.39 \\
\hline HTR3E & chr3 & $-\underline{2.36}$ & -1.49 & -1.15 & -1.09 \\
\hline NUDTI4 & $\operatorname{chrl} 4$ & $-\underline{2.37}$ & -1.58 & -1.45 & -1.35 \\
\hline CKB & chrl4 & $-\underline{2.39}$ & -1.64 & -1.50 & -1.37 \\
\hline LPPR4 & chrl & $-\underline{2.41}$ & -2.10 & -1.66 & -1.37 \\
\hline PIHIDI & chrl9 & $-\underline{2.41}$ & $-\overline{1.73}$ & -1.50 & -1.16 \\
\hline LOCI00505633 & chrl & $-\underline{2.47}$ & -1.74 & -1.41 & -1.35 \\
\hline STMN2 & chr8 & $-\overline{2.48}$ & -2.64 & -1.44 & -1.43 \\
\hline RGS9 & chrl7 & -2.50 & -1.67 & -1.47 & -1.49 \\
\hline TMC6 & chrl7 & $-\overline{2.54}$ & -1.84 & -1.47 & -1.31 \\
\hline SBSN & chrl9 & $-\overline{2.61}$ & $-\underline{2.18}$ & -1.44 & -1.48 \\
\hline LOCI00131138 & $\operatorname{chr} / 2$ & -2.65 & -2.09 & -1.11 & -1.16 \\
\hline SRL & chrl6 & -2.73 & -2.17 & -1.24 & -1.09 \\
\hline LOCI00287628 & chrl 6 & $-\underline{2.75}$ & -1.76 & -1.23 & 1.04 \\
\hline $\mathrm{HOXBI3}$ & chrl7 & $-\underline{2.78}$ & -1.83 & -1.69 & -1.40 \\
\hline TUBB2B & chr6 & $-\underline{2.88}$ & -1.35 & -1.29 & -1.16 \\
\hline CELSRI & chr22 & -2.90 & -1.85 & -1.68 & -1.59 \\
\hline KIFIA & $\operatorname{chr} 2$ & $-\underline{2.92}$ & -1.95 & -1.77 & -1.44 \\
\hline KISSI & chrl & $-\overline{2.93}$ & -1.95 & -1.22 & -1.05 \\
\hline WARS2 & chrl & $-\underline{3.02}$ & -1.96 & -1.57 & -1.37 \\
\hline LOCI00270746 & chr6 & $-\underline{3.02}$ & -1.82 & -1.53 & -1.41 \\
\hline $\begin{array}{l}\text { STONI- } \\
\text { GTF2AIL }\end{array}$ & chr2 & $-\underline{3.10}$ & -2.43 & -1.59 & -1.48 \\
\hline QDPR & chr4 & $-\underline{3.15}$ & -1.84 & -1.33 & -1.19 \\
\hline SCAMP5 & $\operatorname{chr} 15$ & $-\underline{3.16}$ & -2.18 & -1.73 & -1.48 \\
\hline EPB4IL3 & $\operatorname{chr} 18$ & $-\underline{3.25}$ & -1.80 & -1.46 & -1.28 \\
\hline CACNAIH & chrl6 & -3.26 & -2.19 & -1.57 & -1.31 \\
\hline TSPAN33 & $\mathrm{chr} 7$ & $-\underline{3.27}$ & -2.10 & -1.43 & -1.31 \\
\hline UCP2 & chrll & $-\overline{3.42}$ & -2.44 & -1.36 & -1.23 \\
\hline NDRG4 & chrl6 & -3.72 & -1.81 & -1.59 & -1.37 \\
\hline MYLIO & chr7 & $-\underline{4.01}$ & -2.05 & -1.28 & -1.12 \\
\hline MYBPC2 & chrl9 & $-\overline{4.18}$ & -2.01 & -1.89 & -1.55 \\
\hline MGP & $\operatorname{chrl} 2$ & $-\underline{4.40}$ & -1.69 & -1.38 & -1.09 \\
\hline AGT & chrl & $-\underline{4.50}$ & -2.24 & -1.94 & $-1.6 \mid$ \\
\hline LINC00162 & chr2I & $-\underline{6.07}$ & -3.12 & -1.70 & -1.35 \\
\hline UGT2BIO & $\mathrm{chr} 4$ & $\underline{2.00}$ & 1.64 & 1.44 & 1.20 \\
\hline KIAAI462 & $\operatorname{chrlo}$ & $\underline{2.02}$ & 1.35 & 1.22 & 1.12 \\
\hline CST6 & chrll & 2.02 & 1.37 & 1.36 & 1.32 \\
\hline AMIGO2 & $\operatorname{chr} / 2$ & 2.09 & 1.35 & 1.15 & 1.17 \\
\hline CBR3 & chr2l & 2.13 & 1.51 & 1.52 & 1.35 \\
\hline ENOSFI & $\operatorname{chr} 18$ & 2.17 & 1.79 & 1.71 & 1.50 \\
\hline GRIAI & chr5 & 2.24 & 1.32 & 1.61 & 1.45 \\
\hline NTNI & $\operatorname{chrl7}$ & 2.28 & 1.57 & 1.50 & 1.25 \\
\hline CXCLI2 & chrlo & $\underline{2.28}$ & 1.39 & 1.63 & 1.30 \\
\hline LOCI00507632 & chr8 & $\underline{2.51}$ & 2.11 & 1.87 & 1.44 \\
\hline POU3F2 & chr6 & 2.59 & 2.53 & 2.27 & 2.31 \\
\hline SSC5D & chrl9 & 3.20 & 2.05 & 1.73 & 1.62 \\
\hline DDX58 & $\operatorname{chr} 9$ & 3.53 & 2.96 & 2.22 & 1.91 \\
\hline TNFRSFI IB & chr8 & 3.69 & 2.65 & 1.72 & 1.42 \\
\hline
\end{tabular}

Underlined fold-changes represent those deemed significant.

A direct relationship was observed between the initial proportion of normal cells in the myoblast mix and the number of hybrid myotubes with a normal phenotype. We then investigated the feasibility of producing myotubes with a normal morphology from mixtures containing either 40 or $60 \%$ normal myoblasts. Higher percentages of normal myoblasts in the mixture were not further investigated based on the limited credibility of such an approach for therapeutical purposes. Symmetrically, we excluded mixtures with lower percentages of normal myoblasts from further investigation since the phenotype of the hyrid myotubes obtained from initial cultures with only $20 \%$ normal myoblasts exhibited a clear FSHD-like 
TABLE 3. KEGG analysis of significantly deregulated pathways in 100\% FSHD myotubes and increasing proportions of normal myoblasts in hybrid myotubes vs. myotubes derived from 100\% normal myoblasts (blue, downregulated pathways, red, upregulated pathways and green, pathways containing both up and downregulated genes)

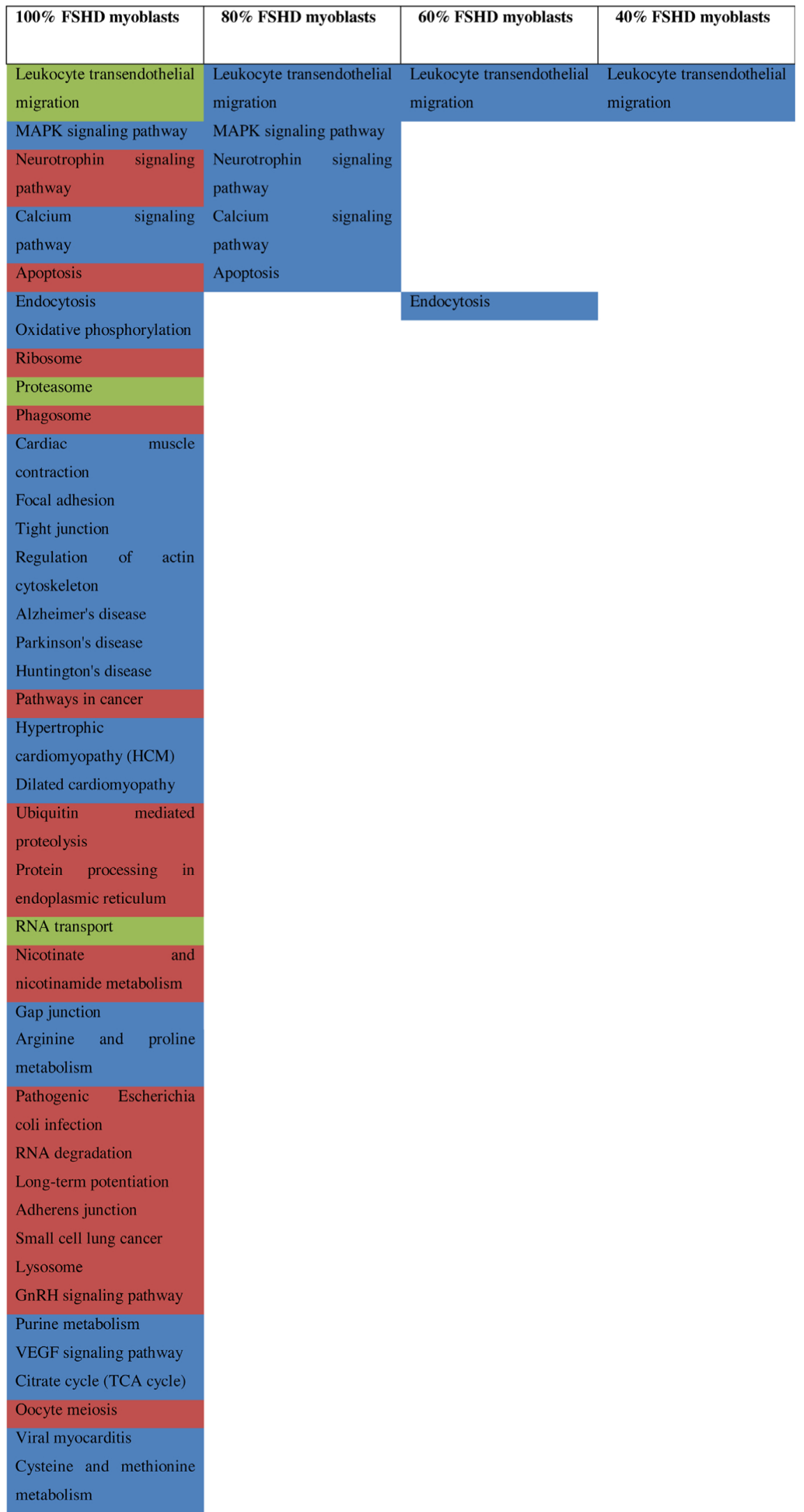


phenotype. From the results here obtained, it appears that the presence of approximately $50 \%$ (or more) of normal myoblasts in the initial culture makes it possible to obtain differentiated hybrid myotubes most or all of which with a normal phenotype.

To analyze these hybrid myotubes at a functional level, we performed transcriptome analysis on normal, FSHD and hybrid myotubes. Comparing FSHD vs. normal myotubes revealed dozens of genes differentially expressed. Down-regulated genes such as MYOZ2, LDB3, REEPI, AGT, SCAMP5, TUBB2B, SRL, STMN2, CKB, HRC, ATP8AI, MGP, NDRG4, CACNAIH, $A Q P I, E P B 4 I L 3$, and $M Y L I O$ are implicated in muscle structure and contraction, in myoblast proliferation and differentiation and are related to cytoskeleton; MYBPC2, THBS4, and RBM20 are implicated in cardiac development and contraction; upregulated genes are also implicated in inflammation (TNFRSFI IB, DDX58, SSC5D, and CXCL / 2); the function of nine of these genes is not known yet (Table 2). The expression of these genes approaches to the normal expression with the increase in the number of normal myoblasts initially cultured.

Based on KEGG analysis, 39 pathways were found deregulated in FSHD vs. normal myotubes. Several of these pathways could result in impaired myogenesis and therefore be partly responsible for the muscular defects in FSHD patients. These included apoptosis, regulation of actin cytoskeleton, RNA transport, RNA degradation, the VEGF signaling and calcium signaling pathways. Among the genes that were deregulated in the MAPK signaling pathway we note $\mathrm{p} 38$ gene that have been described to affect the activities of transcription factors from the MyoD and MEF2 families and to contribute to the temporal expression of genes during differentiation (Keren et al., 2006).

It was striking to note that an increase in the proportion of normal myoblasts in the initial mixture with FSHD-derived myoblasts resulted in myotube transcriptomes revealing a progressively lower number of deregulated pathways. Indeed when $60 \%$ of the initial myoblasts were of normal origin, a single pathway remained deregulated, namely the Leukocyte transendothelial migration pathway. It has not escaped our attention that this pathway is closely associated with an active inflammatory process, a recognized hallmark in FSHD patients. Previous studies indicate that circulating activated immune cells, mainly CD8 $(+) \mathrm{T}$ cells, may favor FSHD progression by promoting active phases of muscle inflammation (Frisullo et al., 20II).

To investigate the dilution effect made by the normal myoblasts we have studied the correlation between theoretical and experimental log ratios of genes expression. Although the majority of correlation coefficients are between I and 0.8 , there are 34 genes with a value between 0.8 and 0.2 . This result is a demonstration that the whole differential expression cannot be explained by a single linear dilution effect and is in part due to changes in genes expression that need to be investigated further.

\section{Conclusions}

In this report, we have demonstrated that it is possible to correct phenotypic and functional defects observed in myotubes derived from 100\% FSHD myoblasts by incorporation of an equivalent proportion of normal myoblasts in the cell mixtures to undergo differentiation in vitro. This was true for functional as well as morphological characteristics. The questions remain, however, whether what can be obtained in vitro can also occur in vivo, and furthermore, whether reaching a proportion of $50 \%$ normal myoblasts in cellular therapy attempts in FSHD patients is possible with available techniques. Since there is no current therapy for FSHD, further studies and investigations are clearly warranted in order to obtain answers to these difficult questions.

\section{Acknowledgements}

This research was supported by the MEGAFSHD grant from the Association Française contre les Myopathies (AFM) to YSV.

\section{Author's contributions}

$C D$, YBS, GC, CR carried out the experiments; CD, PD, ML and $\mathrm{PhD}$ analyzed data; GC, DL contributed cell lines; $C D, Y B S$, GC, CR, PD, PhD, DL, ML contributed to writing the paper; YV conceived, directed the study and participated in writing the paper. All authors read and approved the final manuscript.

\section{Literature Cited}

Arashiro P, Eisenberg I, Kho AT, Cerqueira AM, Canovas M, Silva HC, Pavanello RC Verjovski-Almeida S, Kunkel LM, Zatz M. 2009. Transcriptional regulation differs in affected facioscapulohumeral muscular dystrophy patients compared to asymptomatic related carriers. Proc Natl Acad Sci U S A 106:6220-6225.

Bareja A, Billin AN. 2013. Satellite cell therapy - from mice to men. Skelet Muscle 3:2

Barro M, Carnac G, Flavier S, Mercier J, Vassetzky YS, Laoudj-Chenivesse D. 2010a. Primary myoblasts derived from the facioscapulohumeral dystrophy patients are hypersensitive to oxidative stress and show defects upon terminal differentiation. J Cell Mol Med 14:275-289.

Barro M, Carnac G, Flavier S, Mercier], Vassetzky Y, Laoudj-Chenivesse D. 20I Ob. Myoblasts from affected and non-affected FSHD muscles exhibit morphological differentiation defects. J Cell Mol Med 14:275-289.

Cabianca DS, Casa V, Bodega B, Xynos A, Ginelli E, Tanaka Y, Gabellini D. 2012. A long ncRNA links copy number variation to a polycomb/trithorax epigenetic switch in FSHD muscular dystrophy. Cell 149:819-831.

Deenen JC, Arnts H, van der Maarel SM, Padberg GW, Verschuuren J], Bakker E Weinreich SS, Verbeek AL, van Engelen BG. 20I4. Population-based incidence and prevalence of facioscapulohumeral dystrophy. Neurology 83:1056-1059.

Dmitriev P, Petrov A, Ansseau E, Stankevicins L, Charron S, Kim E, Bos TJ, Robert T, Turki A, Coppée F, Belayew A, Lazar V, Carnac G, Laoudj D, Lipinski M, Vassetzky YS. 20I Ia. The Kruppel-like factor 15 as a molecular link between myogenic factors and a chromosome $4 \mathrm{q}$ transcriptional enhancer implicated in facioscapulohumeral dystrophy. J Biol Chem 286:44620-4463

Dmitriev P, Barat A, Cochet E, Ogryzko V, Laoudj-Chenivesse D, Lipinski M, Vassetzky YS. $201 \mathrm{lb}$. FSHD myoblasts fail to downregulate intermediate filament protein vimentin during myogenic differentiation. Biopolym Cell 27:359-363.

Dmitriev P, Barat A, Polesskaya A, O'Connell MJ, Robert T, Dessen P, Walsh TA, Lazar V, Turki A, Carnac G, et al. 2013. Simultaneous miRNA and mRNA transcriptome profiling of human myoblasts reveals a novel set of myogenic differentiation-associated miRNAs and their target genes. BMC Genomics 14:265

Dmitriev P, Kairov U, Robert T, Barat A, Lazar V, Carnac G, Laoudj-Chenivesse D Vassetzky YS. 2014. Cancer-related genes in the transcription signature of facioscapulohumeral dystrophy myoblasts and myotubes. J Cell Mol Med I8:208-217.

Frisullo G, Frusciante R, Nociti V, Tasca G, Renna R, lorio R, Patanella AK, lannaccone E, Marti A, Rossi M, et al. 20I I. CD8(+) T cells in facioscapulohumeral muscular dystrophy patients with inflammatory features at muscle MRI. J Clin Immunol 31:155-166.

Gabellini D, Green MR, Tupler R. 2002. Inappropriate gene activation in FSHD: A repressor complex binds a chromosomal repeat deleted in dystrophic muscle. Cell I 10:339-348.

Geng LN, Yao Z, Snider L, Fong AP, Cech JN, Young JM, van der Maarel SM, Ruzzo WL, Gentleman RC, Tawil R, et al. 2012. DUX4 activates germline genes, retroelements, and immune mediators: Implications for facioscapulohumeral dystrophy. Dev Cell 22:38-5I.

Keren A, Tamir Y, Bengal E. 2006. The p38 MAPK signaling pathway: A major regulator of skeletal muscle development. Mol Cell Endocrinol 252:224-230.

Kisseljova NP, Dmitriev P, Katargin A, Kim E, Ezerina D, Markozashvili D, Malysheva D, Planche E, Lemmers RJ, van der Maarel SM, et al. 2014. DNA polymorphism and epigenetic marks modulate the affinity of a scaffold/matrix attachment region to the nuclear matrix. Eur J Hum Genet 22:1117-II23.

Kowaljow V, Marcowycz A, Ansseau E, Conde CB, Sauvage S, Matteotti C, Arias C, Corona ED, Nunez NG, Leo O, et al. 2007. The DUX4 gene at the FSHDIA locus encodes a pro-apoptotic protein. Neuromuscul Disord 17:611-623.

Masny PS, Chan OY, de Greef JC, Bengtsson U, Ehrlich M, Tawil R, Lock LF, Hewitt JE, Stocksdale J, Martin JH, et al. 20I0. Analysis of allele-specific RNA transcription in FSHD by RNA-DNA FISH in single myonuclei. Eur J Hum Genet 18:448-456.

Osborne RJ, Welle S, Venance SL, Thornton CA, Tawil R. 2007. Expression profile of FSHD supports a link between retinal vasculopathy and muscular dystrophy. Neurology 68:569-577

Petrov A, Pirozhkova I, Carnac G, Laoudj D, Lipinski M, Vassetzky YS. 2006. Chromatin loop domain organization within the $4 \mathrm{q} 35$ locus in facioscapulohumeral dystrophy patients versus normal human myoblasts. Procof Natl Acad Sci USA 103:6982-6987.

Petrov A, Allinne J, Pirozhkova I, Laoudj D, Lipinski M, Vassetzky YS. 2008. A nuclear matrix attachment site in the $4 \mathrm{q} 35$ locus has an enhancer-blocking activity in vivo: implications for the facio-scapulo-humeral dystrophy. Genome Res 18:39-45.

Rahimov F, King OD, Leung DG, Bibat GM, Emerson CP, Jr., Kunkel LM, Wagner KR. 2012 Transcriptional profiling in facioscapulohumeral muscular dystrophy to identify candidate biomarkers. Proc Natl Acad Sci USA 109:16234-16239.

Rijkers T, Deidda G, van Koningsbruggen S, van Geel M, Lemmers RJ, van Deutekom JC, Figlewicz D, Hewitt JE, Padberg GW, Frants RR, et al. 2004. FRG2, an FSHD candidate gene, is transcriptionally upregulated in differentiating primary myoblast cultures of FSHD patients. J Med Genet 41:826-836.

Snider L, Geng LN, Lemmers RJ, Kyba M, Ware CB, Nelson AM, Tawil R, Filippova GN, van der Maarel SM, Tapscott SJ, et al. 20 I0. Facioscapulohumeral dystrophy: Incomplete suppression of a retrotransposed gene. PLoS Genet 6:e I00 I I8I.

Tassin A, Leroy B, Laoudj-Chenivesse D, Wauters A, Vanderplanck C, Le Bihan MC, Coppee F, Wattiez R, Belayew A. 2012. FSHD myotubes with different phenotypes exhibit distinct proteomes. PLoS ONE 7:e51865. 
Tassin A, Laoudj-Chenivesse D, Vanderplanck C, Barro M, Charron S, Ansseau E, Chen YW Mercier J, Coppée F, Belayew A. 2013. DUX4 expression in FSHD muscle cells: How could such a rare protein cause a myopathy? J Cell Mol Med 17:76-89.

Tawil R, van der Maarel SM, Tapscott SJ. 20|4. Facioscapulohumeral dystrophy: The path to consensus on pathophysiology. Skelet Muscle 4:I2.

Thijssen PE, Balog J, Yao Z, Pham TP, Tawil R, Tapscott SJ, Van der Maarel SM. 20I4. DUX4 promotes transcription of FRG2 by directly activating its promoter in

facioscapulohumeral muscular dystrophy. Skelet Muscle 4:19.

Tsuji M, Kinoshita M, Imai Y, Kawamoto M, Kohara N. 2009. Facioscapulohumeral muscula! dystrophy presenting with hypertrophic cardiomyopathy: A case study. Neuromuscul Disord 19:140-142

Tsumagari K, Chang SC, Lacey M, Baribault C, Chittur SV, Sowden J, Tawil R, Crawford GE Ehrlich M. 20II. Gene expression during normal and FSHD myogenesis. BMCMed Genomics 4:67.

Turki A, Hayot M, Carnac G, Pillard F, Passerieux E, Bommart S, De Mauverger ER, Hugon G Pincemail J, Pietri S, et al. 20।2. Functional muscle impairment in facioscapulohumeral muscular dystrophy is correlated with oxidative stress and mitochondrial dysfunction. Free Radic Biol Med 53:1068-1079.

Van Overveld PG, Lemmers RJ, Sandkuijl LA, Enthoven L, Winokur ST, Bakels F, Padberg GW, van Ommen GJ, Frants RR, van der Maarel SM. 2003. Hypomethylation of D4Z4 in $4 \mathrm{q}$-linked and non-4q-linked facioscapulohumeral muscular dystrophy. Nat Genet 35:315-317.

Wijmenga C, Padberg GW, Moerer P, Wiegant J, Liem L, Brouwer OF, Milner EC, Weber JL van Ommen GB, Sandkuyl LA, et al. I991. Mapping of facioscapulohumeral muscular dystrophy gene to chromosome 4 q35-qter by multipoint linkage analysis and in situ hybridization. Genomics 9:570-575

Winokur ST, Chen YW, Masny PS, Martin JH, Ehmsen JT, Tapscott SJ, van der Maarel SM, Hayashi Y, Flanigan KM. 2003. Expression profiling of FSHD muscle supports a defect in specific stages of myogenic differentiation. Hum Mol Genet 12:2895-2907.

Yip DJ, Picketts DJ. 2003. Increasing D4Z4 repeat copy number compromises $\mathrm{C} 2 \mathrm{Cl} 2$ myoblast differentiation. FEBS Lett 537:133-138. 